\title{
STRATEGI BANK DALAM MENCAPAI LOYALITAS NASABAH MELALUI PENGARUH CITRA, KUALITAS PELAYANAN DAN KEPUASAN NASABAH (STUDI PADA BANK BRI CABANGPURWOKERTO)
}

\author{
Dahlan Hidayat ${ }^{1}$, Agus Suroso $^{2}$, Ade Banani ${ }^{3}$ \\ ${ }_{1}^{1}$ Magister Manajemen, Fakultas Ekonomi dan Bisnis, Universitas Jenderal Soedirman \\ 2,3Dosen Jurusan Manajemen, Fakultas Ekonomi dan Bisnis, Universitas Jenderal Soedirman \\ *Email corresponding author: go_dahlan@yahoo.com
}

\begin{abstract}
Abstrak
Penelitian ini bertujuan untuk mengetahui pengaruh citra dan kualitas pelayanan, terhadap loyalitas konsumen melalui kepuasan konsumen sebagai variabel intervening. Penelitian ini dilakukan di Bank BRI Cabang Purwokerto. Responden dalam penelitian ini adalah nasabah Bank BRI Cabang Purwokerto. Dengan menggunakan teknik pengambilan sampel yang disebut random sampling, jumlah responden dalam penelitian ini adalah 144 orang. Penelitian ini menggunakan Structural Equation Model (SEM). SEM merupakan kombinasi antara analisis faktor dan regresi berganda. Proses permodelan SEM mensyaratkan adanya ukuran sampel, normalitas tidak adanya outliers serta tidak ada masalah dalam multikolinearity dan singularity.Hasil penelitian menunjukkan bahwa kualitas pelayanan berpengaruh signifikan terhadap loyalitas konsumen melalui kepuasan konsumen dan citra berpengaruh signifikan terhadap loyalitas konsumen melalui kepuasan konsumen. Simpulan dari penelitian ini terbukti bahwa kepuasan konsumen memiliki peran sebagai variabel intervening antara citra dan kualitas pelayanan terhadap loyalitas konsumen. Disarankan untuk memperluas ruang lingkup penelitian tidak hanya pada satu jenis perbankan tetapi mencakup perbankan lainnya. Dan untuk manajemen Bank BRI Cabang Purwokerto sebaiknya melakukan mempertahankan citra dan meningkatkan kualitas pelayanan.

Kata Kunci: Citra, Kualitas Pelayanan, Kepuasan Konsumen,Loyalitas Konsumen
\end{abstract}

\begin{abstract}
The aims of the research to investigate the influence of the image and service quality on consumer loyalty of the Bank BRI Cabang Purwokerto through consumer satisfaction as an intervening variable. This research was conducted at the Bank BRI Cabang Purwokerto.The respondents in this study are the customer of Bank BRI Cabang Purwokerto. By using sampling technique which is called random sampling, the numbers of the respondent of this research are 144 people. This research used Structural Equation Models (SEM). SEM is a combination of multiple regression and factor analysis. These results indicate that the image significantly to consumer loyalty through customer satisfaction and the quality of service effect significantly to consumer loyalty through customer satisfaction, The conclusions of this study proved that customer satisfaction has a role as an intervening variable between service qualityand image to customer loyalty.Recommended for further researchers to expand the scope of the research is not just one bank but include other banks as the comparison. Then for the management of Bank BRI Cabang Purwokerto should maintain the bank image and improve service quality.

Keyword: Image, Service Quality, Consumer Satisfaction, Consumer Loyalty
\end{abstract}

\section{PENDAHULUAN}

Persaingan antar bank saat ini semakin ketat. Saat ini, tumbuh dan berkembangnya bank tidak hanya ditandai dengan banyaknya kantor cabang yang dibuka tetapi dapat dilihat dari munculnya berbagai produk baru dengan segala macam atribut yang dimiliki oleh setiap bank seperti memberikan bunga yang tinggi, jaminan kredit, berbagai hadiah, fasilitas on line, phone banking, anjungan tunai mandiri (ATM), serta fasilitas lainnya. Perbankan pada saat ini dituntut untuk semakin meningkatkan pelayanannya, karena nasabah semakin meningkat mobilitas dan kebutuhannya.

Loyalitas nasabah menjadi tujuan utama perusahaan untuk mengembangkan bisnisnya, karena kekuatan nasabah merupakan kunci sukses dari bisnis perbankan. Loyalitas pelanggan 
merupakan faktor penting dalam kelangsungan hidup bisnis dan pengembangan lingkungan yang kompetitif (Bilika et al,.2016).

Salah satu faktor yang mempengaruhi nasabah untuk memilih bank tertentu selain produk yag dimunculkan oleh bank juga dipengaruhi oleh kualitas pelayanan. Kualitas pelayanan merupakan salah satu faktor kunci bagi keberhasilan Bank sebagai perusahaan jasa yaitu dengan menempatkan masalah kepuasan dan loyalitas terhadap nasabah melalui pelayanan sebagai salah satu komitmen bisnisnya.

Bank BRI Cabang Purwokerto adalah perusahaan yang bergerak di bidang jasa keuangan, yang berupaya memberikan pelayanan yang terbaik dengan menjadikan "melayani dengan setulus hati" sebagai slogan yang memotivasi para karyawannya. Fenomena yang melatar belakangi permasalahan penelitian ini adalah Indonesian Bank Loyalitas Index (IBLI) 2018, dari hasil survey, 11 bank berhasil meraih indeks satisfaction, loyalty, dan engagement (SLE) tertinggi. Ke-11 bank tersebut yaitu terdiri atas 3 bank umum kelompok BUKU 4, 3 bank umum kelompok BUKU 3, 2 bank umum syariah (BUS), dan 3 bank pembangunan daerah (BPD), berdasarkan hasil survey tersebut Bank BRI tidak termasuk sebagai bank yang memiliki tingkat loyalitas yang tinggi.(Infobank, Mei 2018)

Penelitian ini dilakukan karena adanya fenomena research gap (hasil penelitian yang berbeda) antara lain penelitiandilakukan oleh Gracia (2012) menunjukkan bahwa variabel citra berpengaruh positif signifikan terhadap loyalitas. Sedangkan penelitianChasbulloh (2013) menunjukkan bahwa citra perusahaan berpengaruh positif tidak signifikan terhadap loyalitas pelanggan.

Berdasarkan latar belakang tersebut, maka penelitian ini mencoba meneliti hubungan antara variabel citra, kualitas pelayanan terhadap loyalitas pelanggan dengan kepuasan pelanggan sebagai variabelmediansi.

\section{TINJAUAN PUSTAKA DAN PERUMUSAN HIPOTESIS}

\section{Citra}

Sutisna (2011:331) mendefinisikan citra sebagai gambaran mental atau konsep tentang sesuatu. Citra dapat diukur melalui pendapat, kesan, atau respon seseorang dengan tujuan untuk mengetahui secara pasti apa yang ada dalam pikiran individu mengenai suatu objek. Bagaimana mereka memahaminya dan apa yang mereka sukai dan tidak disukai dari objek tersebut.

Proses terbentuknya citra perbankan menurut Hawkins etal. (2010) adalah sebagai berikut. Pertama, objek mengetahui (melihat atau mendengar) upaya yang dilakukan perbankan dalam membentuk citra perbankan.Kedua, memperhatikan upaya perbankan tersebut.Ketiga, setelah adanya perhatian objek, mencoba memahami semua yang ada pada upaya perbankan. Keempat, terbentuknya citra perbankan pada objek yang kemudian tahap kelima citra perbankan terbentuk akan menentukan perilaku objek sasaran dalam hubungannya dengan perusahaan.

\section{Kualitas Pelayanan}

Kepuasan pelanggan atas layanan, kinerja pelayanan dan kualitas pelayanan saling berkaitan satu dengan yang lainnya. Kualitas pelayanan akan menentukan seberapa besar kepuasan pelanggan dan mencerminkan kinerja dari pelayanan. Fandy Tjiptono (2012: 178) menyebutkan dalam bukunya bahwa kualitas merupakan"Suatu kondisi dinamis yang berhubungan dengan produk, jasa, manusia, proses, dan lingkungan yang memenuhi atau melebihi harapan. Konsep kualitas meliputi usaha memenuhi harapan pelanggan, mencangkup produk jasa, manusia, proses dan lingkungan. Selain itu kualitas merupakan kondisi yang selalu berubah, misalnya apa yang dianggap merupakan kualitas saat ini mungkin dianggap kurang berkualitas pada masa mendatang".

Berdasarkan kaitannya dengan kantor Bank BRI cabang Purwokerto sebagai penyedia jasa pelayanan diharapkan dapat memberikan pelayanan yang menyenangkan dan nyaman bagi para nasabahnya. Oleh karena itu, yang digunakanadalah teori Service Quality 
(Servqual).Metode SERVQUAL adalah metode yang sering digunakan untuk mengukur kualitas pelayanan.

\section{Kepuasan Nasabah}

Tjiptono (2012 : 349) mengemukakan bahwa: " Kepuasan nasabah adalah tanggapan emosional pada evaluasi terhadap pengalaman konsumsi suatu produk atau jasa." Ketika nasabah membeli suatu produk, maka ia memiliki harapan tentang bagaimana produk tersebut berfungsi (product performance).Seorang nasabah yang puas adalah nasabah yang merasa mendapatkan value dari pemasok, produsen atau penyedia jasa.Value ini bisa berasal dari produk, pelayanan, sistem atau sesuatu yang bersifat emosi.Kalau nasabah mengatakan bahwa value adalah produk yang berkualitas, maka kepuasan terjadi kalau nasabah mendapatkan produk yang berkualitas. Kalau value bagi nasabah adalah kenyamanan, maka kepuasan akan datang apabila pelayanan yang diperoleh benar-benar nyaman. Kalau value dari nasabah adalah harga yang murah, maka nasabah akan puas kepada produsen yang memberikan harga yang paling kompetitif.

Secara sederhana, tingkat kepuasan seseorang nasabah terhadap produk tertentu merupakan hasil dari perbandingan yang dilakukan oleh nasabah bersangkutan atas tingkat manfaat yang dipersepsikan (perceived) telah diterima setelah mengkonsumsi atau menggunakan produk dan tingkat manfaat yang diharapkan (expected) sabelum pembelian jasa. Jika persepsi sama atau lebih besar dibandingkan harapan, maka nasabah akan merasa puas.

\section{Loyalitas Pelanggan}

Menurut Kotler dan Armstrong (2015:49) menjaga pelanggan tetap loyal masuk akal secara ekonomi.Pelanggan yang loyal menggunakan produk perusahaan lebih banyak dan dalam waktu yang lebih lama. Kehilangan pelanggan yang loyal dapat berarti kehilangan aliran pendapatan akan pelanggan tersebut di masa datang. Ishaq et al. (2014) mengatakan loyalitas adalah sebuah proses, pada akhir proses tersebut, kepuasan mempunyai efek pada perceived quality, yang dapat memberikan dampak kepada loyalitas dan niat untuk perilaku tertentu dari seorang pelanggan.

Alasan lain yang menyebabkan pelanggan tidak loyal adalah multibrand loyalty, berpindahnya pelanggan dari sebuah kategori produk sebagai contoh seorang pelanggan yang berhenti merokok dan adanya perubahan pada kebutuhan konsumen. Lebih jauh perubahan pada konsumen contohnya adalah seorang anak - anak yang berubah menjadi dewasa produk yang digunakan seperti mainan anak - anak akan berubah menyesuaikan perkembangan anak tersebut.

\section{Hipotesis}

H1 : Terdapat pengaruh antara citra terhadap kepuasan nasabah Bank BRI Cabang Purwokerto

H2: Terdapat pengaruh antara kualitas pelayanan terhadap kepuasan nasabah Bank BRI Cabang Purwokerto.

H3 : Terdapat pengaruh antara citra terhadap loyalitas pelanggan Bank BRI Cabang Purwokerto

H4 : Terdapat pengaruh antara kualitas pelayanan terhadap loyalitas pelanggan Bank BRI Cabang Purwokerto

H5 : Terdapat pengaruh antara kepuasan nasabah terhadap loyalitas pelanggan Bank BRI Cabang Purwokerto

H6 : Terdapat pengaruh antara citra terhadap loyalitas nasabah Bank BRI Cabang Purwokerto melalui kepuasan nasabah sebagai variabel mediasi.

H7: Terdapat pengaruh antara kualitas pelayanan terhadap loyalitas nasabah Bank BRI Cabang Purwokerto melalui kepuasan nasabah sebagai variabel mediasi. 


\section{Pengembangan Model Penelitian}

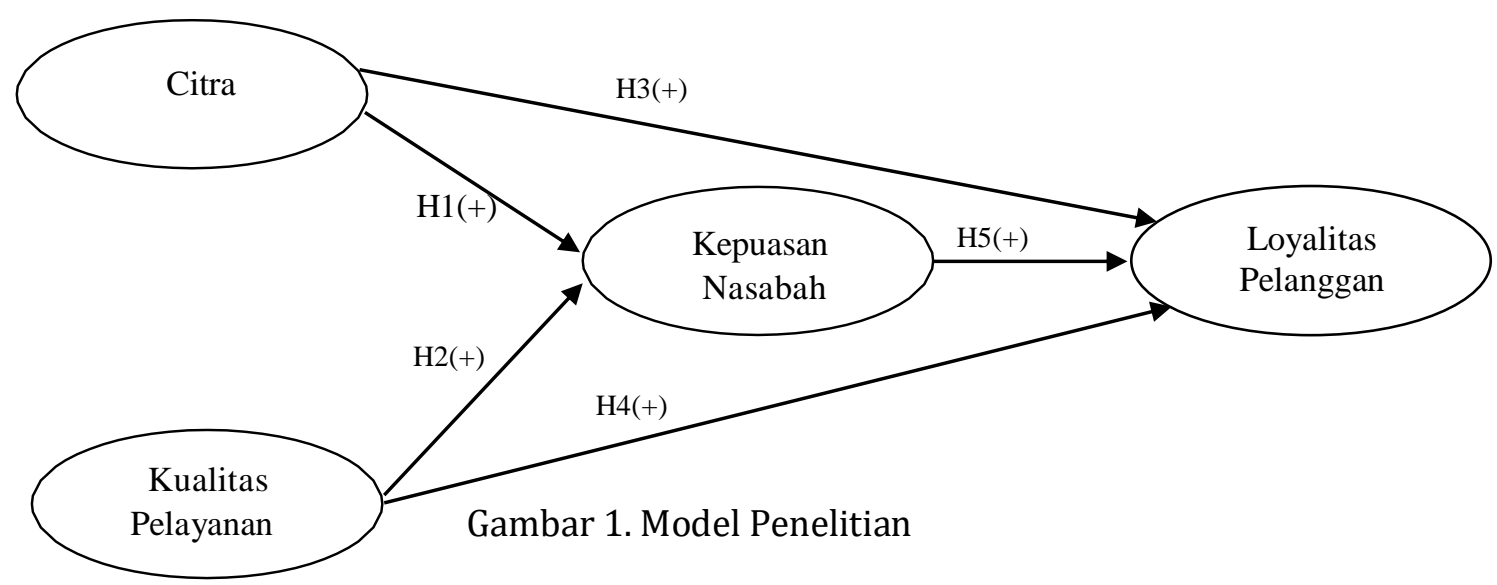

\section{METODE PENELITIAN}

\section{Jenis Penelitian}

Jenis penelitian ini adalah deskriptif dengan metode kuantitatif.

\section{Lokasi Penelitian}

Penelitian ini dilakukan di Bank BRI Cabang Purwokerto. Periode pengamatan dalam penelitian ini pada bulan November sampai dengan Desember 2018.

\section{Metode dan teknik pengambilan Sampel}

Populasi dalam penelitian ini adalah nasabah Bank BRI Cabang Purwokerto. Berdasarkan Hair et al, (1995),bahwa sampel yang diambil dikalikan 5-10 jumlah indikator. Penelitian inimenggunakan jumlah 6 kali parameter yang digunakan dalam penelitian untuksampel.Dengan menggunakan parameter inti pertanyaan, maka jumlah yangdiambil adalah $24 \times 6=144$ sampel, yaitu ukuran sample yang sesuai untuk SEM adalah 100200.Metode pemilihan sampelyang digunakan adalah random sampling yaitu pengambilan sampel dengan secara acak oleh peneliti saat melakukan penelitian dan mau dijadikan responden.

\section{Teknik Pengumpulan Data}

Teknik pengumpulan data yang dipakai dalam penelitian ini dilakukan dengan interview (wawancara) dengan kuisioner (daftar pertanyaan).

\section{Metode Analisis Data}

Dalam penelitian ini metode yang digunakan adalah Structural Equation Model (SEM).

\section{HASIL DAN PEMBAHASAN}

\section{Gambaran Umum Lokasi Penelitian}

Saat ini Bank Rakyat Indonesia Cabang Purwokerto telah mampu melayani berbagai macam jasa pelayanan perbankan dengan menggunakan sistem pembukuan Brinets yang diimplementasikan pada tanggal 4 Maret 2002. Untuk pelayanan ATM (Automatic Teller Machine/Anjungan Tunai Mandiri) BRI Kanca Purwokerto mempunyai ATM yang tersebar di tiap kantor BRI Unit dan di pusat-pusat keramaian. Bertitik tolak dari potensi dan kondisi wilayah kerjanya, tentunya tidak dapat dihindari adanya persaingan dengan bank lain, mengingat hampir semua perbankan di Indonesia membuka kantor cabang di Purwokerto. Untuk itu mutlak diperlukan adanya pelayanan yang lebih baik dan prima yang dalam hal ini peranan Sumber Daya Manusia yang terlatih, memegang peran utama.Selain itu, fasilitas / sarana dan prasarana gedung beserta kelengkapannya merupakan faktor pendukung yang tidak kalah pentingnya dalam rangka meningkatkan pelayanan. 


\section{Hasil Penelitian}

Analisis Structural Equation Modeling (SEM)

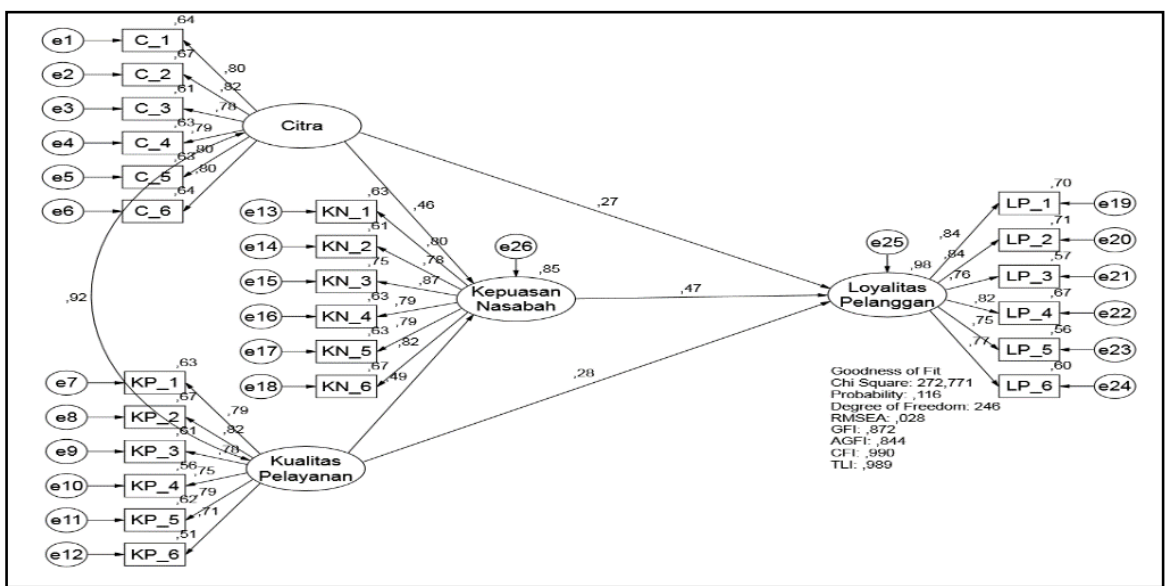

Gambar 2. Full Model Persamaan Struktural

Setelah model dianalisis melalui Confirmatory Factor Analysis serta dapat dilihat bahwa ada beberapa indikator yang tidak dapat digunakan untuk mendefinisikan konstruk laten yang akhirnya dikeluarkan dari model, maka sebuah full model SEM dapat dikembangan untuk kemudian dilakukan analisis. Hasil pengolahan dengan menggunakan program komputer AMOS versi 18 tampak pada Gambar 2. Pengujian SEM dilakukan dengan dua macam pengujian, yaitu kesesuaian model serta uji signifikansi kausalitas melalui uji koefisien regresi.

Uji Kesesuaian Model (Goodness of Fit Test)

Uji terhadap kesesuaian model menunjukkan bahwa sebuah model sesuai atau fit terhadap data yang digunakan dalam penelitian. Hal ini terlihat dari kriteria yang ada yaitu Chi-Square, Probability, CMIN/DF, GFI, AGFI, TLI, CFI, dan RMSEA, apakah semuanya diterima secara baik. Menurut Hair,et al. (2010) uji kesesuaian model ini dapat diterima atau model dikategorikan fit apabila minimal 5 kriteria tersebut terpenuhi.

Tabel 1. Hasil Uji Kesesuaian Model (Goodness of Fit Test)

\begin{tabular}{cccc}
\hline $\begin{array}{c}\text { Goodness-of-fit } \\
\text { index }\end{array}$ & $\begin{array}{c}\text { Hasil } \\
\text { Model } \\
\text { Penelitian }\end{array}$ & Cut of Value & Keterangan \\
\hline Chi-Square & 272,771 & $<283,586$ & Baik \\
\hline Significant probability & 0,116 & $\geq 0,05$ & Baik \\
\hline$R M S E A$ & 0,028 & $\leq 0,08$ & Baik \\
\hline GFI & 0,872 & $\geq 0,90$ & Marginal \\
\hline AGFI & 0,844 & $\geq 0,90$ & Marginal \\
\hline CMIN/DF & 1,109 & $\leq 2,00$ & Baik \\
\hline TLI & 0,989 & $\geq 0,95$ & Baik \\
\hline CFI & 0,990 & $\geq 0,95$ & Baik \\
\hline
\end{tabular}

Penjelasan lebih lanjut dari tabel di atas adalah sebagai berikut:

Nilai $X^{2}$ Chi-Square yang dihasilkan adalah sebesar 272,771. Angka ini diterima secara baik, nilai $272,771<283,586$. Sehingga dapat disimpulkan bahwa model dalam penelitian ini termasuk a very good fit karena nilai probability lebih kecil dari 283,586. Jadi model yang dihipotesiskan sesuai dengan data. 


\section{Probability}

Nilai probability yang dihasilkan adalah 0,116 dan nilai ini di atas cut-of valuenya $(0,05)$, sehingga model diterima secara baik. Hal ini mengindikasikan tidak adanya perbedaan yang signifikan antara matriks kovarian data dan matriks kovarian yang diestimasi. CMIN/DF (The Minimum Sample Of Discrepancy Funtion devide with Degree of Freedom) Nilai CMIN/DF yang dihasilkan adalah sebesar 1,109 dan angka ini kurang dari 2,0 yang mengindikasikan acceptabel fit antara model dengan data. Model dapat diterima dengan baik.

\section{GFI (Goodness-of-Fit Index)}

Nilai GFI yang dihasilkan adalah sebesar 0,872 dan nilai ini dibawahcut-of valuenya $(0,90)$. Nilai GFI ini menunjukkan proporsi tertimbang dari varians dari matriks kovarian sampel yang dijelaskan oleh matriks populasi yang diestimasikan. Nilai yang dihasilkan di bawah good fit dan berada pada posisi marginal, namun model masih dapat diterima.

\section{AGFI}

Nilai AGFI ini menunjukan proporsi tertimbang dari varians dalam matriks sampel yang dijelaskan oleh matriks populasi yang diestimasikan. AGFI yang dihasilkan adalah sebesar 0,844 dan nilai ini dibawah cut-of valuenya $(0,90)$. Tetapi nilai ini masih dapat diterima dan model dapat diterima walaupun secara marginal.

\section{TLI (Tucker Lewis Index)}

Nilai TLI yang dihasilkan sebesar 0.989 dan nilai ini diatas nilai cut-of valuenya $(0,95)$. Model dapat diterima secara very good fit. Nilai TLI merupakan indeks yang membandingkan sebuah model yang diuji terhadap sebuah baseline model.

\section{CFI (Comparative Fit Index)}

Nilai CFI yang dihasilkan sebesar 0.990 dan nilai ini diatas nilai cut-of valuenya $(0,95)$. Model dapat diterima secara very good fit. Nilai CFI merupakan indeks yang membandingkan sebuah model yang diuji terhadap sebuah baseline model.

\section{RMSEA (The Root Mean Square Error of Approximation)}

Nilai RMSEA yang dihasilkan adalah sebesar 0,028 dan nilai ini kurang dari 0,08. Model dapat diterima secara very good fit.

Uji Kausalitas Full Model : Regression Test

Hubungan pengaruh model lengkap yang dikembangkan dalam penelitian ini perlu diuji hipotesis nol $\left(\mathrm{H}_{0}\right)$ melalui uji t yang lazim dalam model-model regresi. Berdasarkan hasil analisis, regression weight dan nilai-nilai koefisien regresi fullmodel dapat dilihat dalam Tabel 4.12 di mana hasil tersebut dapat dilihat pada Text Output $>$ Estimates program komputer AMOS 18. Kriteria pengujiannya adalah membandingkan nilai $\mathrm{P}$ dengan tingkat signifikansi yang digunakan dalam penelitian ini yaitu sebesar $99 \%$ $(0,01)$. Jika nilai $P \geq 0,01$ maka disimpulkan bahwa tidak ada hubungan pengaruh antar dua variabel. 
Tabel 2. Hasil Uji Kausalitas Full Model : Regression Test

\begin{tabular}{lccrrrr}
\hline & & & Estimate & S.E. & C.R. & P Label \\
\hline Kepuasan_Nasabah & $<---$ & Citra & 0,432 & 0,164 & 2,632 & 0,008 \\
\hline Kepuasan_Nasabah & $<---$ & Kualitas_Pelayanan & 0,493 & 0,176 & 2,795 & 0,005 \\
\hline Loyalitas_Pelanggan & $<---$ & Kepuasan_Nasabah & 0,464 & 0,122 & 3,806 & $* * *$ \\
\hline Loyalitas_Pelanggan & $<---$ & Citra & 0,252 & 0,127 & 1,979 & 0,048 \\
\hline Loyalitas_Pelanggan & $<---$ & Kualitas_Pelayanan & 0,279 & 0,14 & 1,985 & 0,047 \\
\hline
\end{tabular}

Sumber: Lampiran 5

Pengujian hipotesis ini dilakukan dengan dasar hasil pengolahan data dalam penelitian dengan menggunakan analisis SEM. Secara umum, pengujian hipotesis ini dilakukan dengan menganalisis nilai critical ratio (C.R) dan nilai probabilitas (P) sebagai hasil dari pengolahan data yang dibandingkan dengan batasan statistik yang disyaratkan. Nilai critical ratio yang dipersyaratkan adalah di atas 1,980 dan nilai probabilitas yang disyaratkan adalah di bawah 0,01. Jika hasil dari pengolahan data memenuhi persyaratan tersebut, maka hipotesis dalam penelitian yang diajukan ini dinyatakan dapat diterima.

Pengujian hipotesis dalam penelitian ini akan dibahas secara terperinci dan bertahap sesuai dengan urutan-urutan hipotesis yang diajukan. Pada bagian akhir akan dibahas kesimpulan umum atas permasalahan dan cakupan penelitian serta signifikansi hipotesis berdasar angka statistik yang ada. Adapun pembahasan hasil pengujian hipotesis berdasarkan Tabel 2 di atas adalah sebagai berikut:

Pengaruh kualitas pelayanan terhadap kepuasan nasabah Hipotesis diterima karena pada Tabel 2 nilai C.R untuk pengaruh variabel kualitas pelayanan terhadap kepuasan nasabah adalah lebih besar dari nilai $t_{\text {tabel }}$, yaitu C.R> $t_{\text {tabel }}(2,795>1,980)$.

Pengaruh citra terhadap kepuasan nasabah Hipotesis diterima karena pada Tabel 2 nilai C.R untuk pengaruh variabel citra terhadap kepuasan nasabah adalah lebih besar dari nilai $t_{\text {tabel }}$, yaitu C.R $>t_{\text {tabel }}$ $(2,632>1,980)$.

Pengaruh citra terhadap loyalitas pelanggan Hipotesis ditolak karena pada Tabel 2 nilai C.R untuk pengaruh variabel citra terhadap loyalitas pelanggan adalah kurang dari nilai $t_{\text {tabel }}$, yaitu C.R $<t_{\text {tabel }}(1,979<1,980)$.

Pengaruh kualitas pelayanan terhadap loyalitas pelanggan Hipotesis diterima karena pada Tabel 2 nilai C.R untuk pengaruh variabel kualitas pelayanan terhadap loyalitas pelanggan adalah lebih dari dari nilai $t_{\text {tabel }}$, yaitu C.R $>t_{\text {tabel }}$ $(1,985>1,980)$.

Pengaruh kepuasan nasabah terhadap loyalitas pelanggan Hipotesis diterima karena pada Tabel 2 nilai C.R untuk pengaruh variabel kepuasan nasabah terhadap loyalitas pelanggan adalah lebih besar dari nilai $t_{\text {tabel }}$, yaitu C.R $>t_{\text {tabel }}$ $(3,806>1,980)$. 
Tabel 3. Koefisien Jalur Terstandarisasi

\begin{tabular}{|c|c|c|c|c|c|c|c|c|}
\hline & & & & & Total & Direct & Indirect & Ket \\
\hline Citra & $\rightarrow$ & $\begin{array}{c}\text { Kepuasan } \\
\text { Nasabah }\end{array}$ & $\rightarrow$ & $\begin{array}{l}\text { Loyalitas } \\
\text { Pelanggan }\end{array}$ & 0,483 & 0,269 & 0,214 & $\begin{array}{c}\text { Memedias } \\
\text { i }\end{array}$ \\
\hline $\begin{array}{c}\text { Kualitas } \\
\text { Pelayana } \\
\text { n }\end{array}$ & $\rightarrow$ & $\begin{array}{c}\text { Kepuasan } \\
\text { Nasabah }\end{array}$ & $\rightarrow$ & $\begin{array}{l}\text { Loyalitas } \\
\text { Pelanggan }\end{array}$ & 0,508 & 0,279 & 0,229 & $\underset{\mathrm{i}}{\text { Memedias }}$ \\
\hline
\end{tabular}

Pengaruh citra terhadap loyalitas nasabah melalui kepuasan nasabah sebagai variabel mediasi

Hipotesis diterima karenadari tabel 3 , inderect effect $(0,214)$ sehingga peranan citra terhadap loyalitas nasabah melalui kepuasan nasabah sebagai variabel mediasi adalah 0,214 .

Pengaruh kualitas pelayanan terhadap loyalitas nasabah melalui kepuasan nasabah sebagai variabel mediasi

Hipotesis diterima karena dari tabel 3 , inderect effect $(0,229)$ sehingga perananan kualitas pelayanan terhadap loyalitas nasabah melalui kepuasan nasabah sebagai variabel mediasi adalah 0,229.

\section{Pembahasan}

Pembahasan Model

Berdasarkan hasil statistik analisis SEM dalam uji kesesuaian model-goodnessof-fit test,dari delapan kriteria, diperoleh enam kriteria yang masuk dalam kategori baik yaitu Chi-square, probabilty, RSMEA, CMIN/DF,TLI dan CFI. Sementara GFI dan AGFI mendekati nilai acuan. Model dapat diterima secara good fit.

\section{Pembahasan Hipotesis}

\section{Pengaruh kualitas pelayanan terhadap kepuasan nasabah}

Hasil penelitian menunjukkan pengaruh variabel kualitas pelayanan terhadap kepuasan nasabah adalah lebih besar dari nilai $t_{\text {tabel }}$, yaitu C.R $>t_{\text {tabel }}(2,795>1,980)$. Oleh karena itu, hipotesis pertama yang menyatakan Terdapat pengaruh antara kualitas pelayanan terhadap kepuasan nasabah Bank BRI Cabang Purwokerto diterima.

Penelitian lain yang senada adalah penelitian Bedi (2010) mengusulkan bahwa pengiriman layanan berkualitas tinggi adalah suatu keharusan untuk mencapai kepuasan pelanggan dan sejumlah hasil perilaku yang diinginkan lainnya.Penelitian ini berjudul "The Effect of Perceived Service Quality Dimensions on Customer Satisfaction, Trust, And Loyalty in E-Commerce Settings." Penelitian ini secara empiris bertujuan untuk menyelidiki hubungan antara kualitas layanan yang dirasakan, kepuasan, kepercayaan, dan loyalitas pelanggan dalam pengaturan e-commerce dalam dua budaya - Malaysia dan Qatar - pada tingkat dimensi konstruk. Variabel yang digunakan dalam penelitian ini meliputi kualitas layanan, kepuasan, kepercayaan, dan loyalitas pelanggan. Penelitian ini mengambil lokasi di perusahaan e-commerce di Malaysia dan Arab. Sebuah teknik Convenience Sampling diterapkan untuk pengambilan data dari Malaysia dan Qatar. Hasil penelitian menunjukkan bahwa interaksi antara dimensi kualitas layanan dan budaya tidak signifikan dalam menentukan SAT. Dengan demikian, pengaruh dimensi kualitas layanan terhadap kepuasan pada kedua pengguna Qatar dan Malaysia adalah sama.

Penelitian lain yang mendukung adalah Hafeez (2012). Penelitian dengan judul The Impact of Service Quality, Customer Satisfaction and Loyalty Programs on 
Customer's Loyalty: Evidence from Banking Sector of Pakistan. Hasil penelitian menunjukkan kualitas memberikan suatu dorongan kepada pelanggan untuk menjalin ikatan hubungan yang kuat dengan perusahaan. Dalam jangka panjang, ikatan seperti ini memungkinkan perusahaan untuk memahami dengan seksama harapan pelanggan serta kebutuhan mereka sehingga perusahaan dapat meningkatkan kepuasan pelanggan dengan cara memaksimalkan pengalaman pelanggan yang menyenangkan dan meminimalkan atau meniadakan pengalaman pelanggan yang kurang menyenangkan.

\section{Pengaruh citra terhadap kepuasan nasabah}

Hasil penelitian menunjukkan pengaruh variabel citra terhadap kepuasan nasabah adalah lebih besar dari nilai $t_{\text {tabel }}$, yaitu C.R $>t_{\text {tabel }}(2,632>1,980)$. Oleh karena itu, hipotesis kedua yang menyatakan Terdapat pengaruh antara citra terhadap kepuasan nasabah Bank BRI Cabang Purwokerto, diterima.

Hasil penelitian ini diperkuat oleh penelitian terdahulu seperti Menurut Kurniawati, dkk(2014)menyatakan Brand Imagememiliki pengaruh yang positif terhadap kepuasan konsumen, begitu juga Qomariyah (2012) menyatakan bahwa citra institusi berpengaruh signifikan terhadap kepuasan pelanggan yang dalam hal ini kepuasan mahasiswa.

Penelitian lain yang mendukung adalah Martina et al. (2013) yang berjudul The Quality value,satisfaction, loyalty chain:relationships and impacts. Citra merek (brand image) adalah nama, istilah, tanda, simbol, desain khusus, atau kombinasi dari unsurunsur tersebut yang berfungsi untuk mengidentifikasi produk perusahaan yang tidak hanya membedakannya dari produk pesaing namun merupakan janji produsen atau kontrak. Kepercayaan dari produsen kepada konsumen dengan menjamin konsistensi bahwa sebuah produk akan selalu dapat menyampaikan nilai yang diharapkan konsumen dari sebuah produk.

\section{Pengaruh citra terhadap loyalitas pelanggan}

Hasil penelitian menunjukkan pengaruh variabel citra terhadap loyalitas pelanggan adalah kurang dari nilai $t_{\text {tabel }}$, yaitu C.R $<t_{\text {tabel }}(1,979<1,980)$. Oleh karena itu, hipotesis keempat yang menyatakan Terdapat pengaruh antara citra terhadap loyalitas pelanggan Bank BRI Cabang Purwokerto, ditolak.

Penelitian yang mendukung penelitian ini adalah Chasbulloh (2013) yang berjudul Pengaruh Kualitas Layanan, Kepercayaan Pelanggan, Citra Perusahaan Dengan Kepuasan Terhadap Loyalitas Pada Giant Hypermarket Di Surabaya. Hasil penelitian menunjukkan bahwa citra perusahaan berpengaruh positif tidak signifikan terhadap loyalitas pelanggan. Hal ini berarti meskipun pelanggan merasa image Giant Hypermarket baik belum tentu pelanggan tersebut akan loyal terhadap Giant Hypermarket. Berdasarkan hasil penelitian ini berarti loyalitas pelanggan tidak semata - mata ditentukan oleh citra perusahaan. Hal ini dapat disebabkan oleh karakteristik pelanggan Giant Hypermarket adalah orang-orang yang berbelanja bulanan atau mingguan. Dari krakteristik ini dapat menunjukan bahwa citra yang baik tidak selalu diikuti oleh loyalitas pelanggan.

Hasil penelitian ini bertentangan dengan penelitian Rizwan Ali, Profesor Gao Leifu dan Ramiz ur Rehman dalam penelitian Factors Influencing Customer Loyalty of Banking Industry : Empirical Eviden from Pakistan (2014). Dalam penelitian ini menggunakan analisis anova. Variabel dependen yaitu loyalitas pelanggan sedangkan variabel independennya yaitu kualitas layanan, kepercayaan dan reputasi. Sampel yang 
digunakan yaitu 645 responden. Hasil dari penelitian ini adalah dari ketiga variabel independen menunjukkan bahwa semua mempengaruhi variabel dependen secara positif dan signifikan.

\section{Pengaruh kualitas pelayanan terhadap loyalitas pelanggan}

Hasil penelitian menunjukkan pengaruh variabel kualitas pelayanan terhadap loyalitas pelanggan adalah lebih dari dari nilai $t_{\text {tabel }}$, yaitu C.R $>t_{\text {tabel }}(1,985>1,980)$. Oleh karena itu, hipotesis ketiga yang menyatakan Terdapat pengaruh antara kualitas pelayanan terhadap loyalitas pelanggan Bank BRI Cabang Purwokerto, diterima.

Hasil ini senada dengan penelitian yang dilakukan oleh Sumertana (2016), menunjukan bahwa terdapat pengaruh yang signifikan antara kualitas pelayanan dengan kepuasan pelanggan, kualitas pelayanan dapat berpengaruh langsung terhadap loyalitas pelanggan dan dapat juga berpengaruh tidak langsung melalui kepuasan konsumen (sebagai variabel intervening).

Penelitian lain yang mendukung adalah penelitian Ilias Santouridis dan Panagiotis Trivellas (2010) yang berjudul "Investigating the impact of service quality and customer satisfaction on customer loyalty in mobile telephony in Greece". Tujuan dari penelitian ini untuk mengetahui pengaruh kualitas layanan dan kepuasan terhadap loyalitas pengguna mobile telephone di Yunani. Variabel yang digunakan dalam penelitian ini adalah kualitas pelayanan, kepuasan pelanggan dan loyalitas. Hasil penelitian ini adalah jaringan, layanan nilai tambah, perangkat mobile, layanan pelanggan yang menjadi dimensi kualitas layanan tersebut yang memiliki pengaruh positif yang lebih signifikan pada kepuasan pelanggan, yang pada gilirannya memiliki signifikan berdampak positif terhadap loyalitas pelanggan. Peran mediasi kepuasan pelanggan pada kualitas layanan dan hubungan loyalitas pelanggan juga telah dikonfirmasi.

Pengaruh kepuasan nasabah terhadap loyalitas pelanggan.

Hasil penelitian ini adalah pengaruh variabel kepuasan nasabah terhadap loyalitas pelanggan adalah lebih besar dari nilai $t_{\text {tabel }}$, yaitu C.R $>t_{\text {tabel }}(3,806>1,980)$. Oleh karena itu, hipotesis kelima yang menyatakan Terdapat pengaruh antara kepuasan nasabah terhadap loyalitas pelanggan Bank BRI Cabang Purwokerto, diterima.

Penelitian yang mendukung adalah Kai Chieh Hu and Mei Chieh Huang (2011) meneliti dengan judul Effects of Service Quality, Innovation and Corporate Image on Customer's Satisfaction and Loyalty of Air Cargo Terminal. Hasil dari penelitian menunjukkan bahwa kepuasan pelanggan memiliki statistik pada loyalitas, dan kualitas pelayanan, kemampuan inovasi dan citra perusahaan memiliki efek positif pada kepuasan pelanggan masing-masing.

Penelitian lain yang mendukung adalah penelitian milik Faizan Mohsan, Muhammad Musarrat Nawaz, M. Sarfraz Khan, Zeeshan Shaukat, Numan Aslam (2011) tentang "Impact Of Customer Satisfaction On Customer Loyalty And Intentions To Switch: Evidence From Banking Sector Of Pakistan" yang bertujuan untuk untuk menemukan dampak kepuasan pelanggan terhadap loyalitas pelanggan dan niat untuk beralih. Hasil dari penelitian terdahulu kedua menunjukkan bahwa kepuasan pelanggan berkorelasi positif dengan loyalitas pelanggan dan berkorelasi negatif dengan niat pelanggan untuk beralih. 


\section{Pengaruh Citra terhadap Loyalitas Nasabah melalui Kepuasan Nasabah sebagai Variabel Mediasi}

Hasil penelitian ini adalah inderect effect $(0,214)$ sehingga perananan citra terhadap loyalitas nasabah melalui kepuasan nasabah sebagai variabel mediasi adalah 0,214. Artinya hipotesis keenam yang menyatakan terdapat pengaruh antara citra terhadap loyalitas nasabah PT BRI Cabang Purwokerto melalui kepuasan nasabah sebagai variabel mediasi, diterima dengan pengaruh sebesar 0,214.

Menurut Tutut Ratna (2011),brand image berpengaruh positif dan signifikan terhadap loyalitas pelanggan. Hubungan citra merek dengan loyalitas pelanggan dipengaruhi oleh pengalaman penggunaan produk yang memuaskan. Konsumen yang memiliki loyalitas terhadap suatu merek akan terus melakukan pembelian ulang karena sudah percaya dan merasa puas sehingga konsumen tidak mudah tergiur dengan promosi dari pihak pesaing dan adanya kemauan untuk merekomendasikan merek tersebut kepada orang lain. Sehingga menciptakan dari kepuasaan menjadi loyalitas pelanggan yang di timbulkan dari citra merek tersebut.

Penelitian lain yang mendukung adalah Jahanshahi, Gasthi, Mirdamadi, Nawaser Dan Khaksar (2011) Dalam penelitian ini, peneliti yang menjadi acuan adalah hasil penelitian terdahulu berjudul "Study the Effects of Customer Service and Product Quality on Customer Satisfaction and Loyalty" yang di publikasikan di International Journal of Humanities and Social Science. Populasi penelitian ini adalah semua pemilik mobil Tata Indica di Pune. Hipotesis penelitian akan dianalisis menggunakan regresi dan ANOVA. Hasil penelitian menunjukkan bahwa ada korelasi positif yang tinggi antara konstruk dari layanan pelanggan dan kualitas produk dengan kepuasan dan loyalitas pelanggan.

Penelitian Syaifuddin (2016) berjudul Pengaruh Kualitas Layanan Terhadap Loyalitas Melalui Kepuasan Pelanggan Sebagai Variabel Intervening (Studi kasus : Kereta Jenggala jurusan Mojokerto-Sidoarjo). Kepuasan pelanggan dapat menjadi mediasi hubungan diantara kualitas layanan KA Jenggala dan loyalitas pelanggan.

Penelitian Dimyati (2016) yang berjudul Impact of Service Quality, Price, and Brand on Loyalty with the mediation of Customer Satisfaction on Pos Ekspres in East Java menunjukkan kepuasan konsumen mampu memediasi secara signifikan antara kualitas pelayanan terhadap loyalitas konsumen sehingga dari hasil ini konsumen berpandangan bahwa semakin tinggi kualitas pelayanan yang diberikan maka akan semakin tinggi pula kepuasan konsumen sehingga akan membentuk loyalitas konsumen.Mengacu pada teori pertukaran sosial bahwa seseorang akan membalas perlakuan orang lain termasuk perusahaan terhadap dirinya seperti apa yang perusahaan perlakukan /berikan kepadanya. Nasabah yang merasakan kepuasan dari pelayanan yang diberikan oleh bank, maka nasabah tersebut akan membalas perilaku bank tersebut dengan menunjukan loyalitas seperti pembelian ulang, merekomendasikan kepada orang lain dan berkata positif mengenai bank tersebut. Selain itu, peran variabel pemediasi ini juga mendukung pendapat

Robbins \& Judge (2013) yang menjelaskan bahwa sikap seseorang dibentuk dari tiga komponen yaitu, kognitif/evaluasi, afektif/perasaan dan perilaku/tindakan. Dapat dikatakan bahwa persepsi/evaluasi nasabah terhadap kualitas layanan yang diberikan Bank syariah, akan memunculkan perasaan puas/kognitif yang akan menentukan loyalitas/tindakan dari nasabah.

Pengaruh Kualitas Pelayanan terhadap Loyalitas Nasabah melalui Kepuasan Nasabah sebagai Variabel Mediasi

Hasil penelitian ini adalah inderect effect $(0,229)$ sehingga perananan Kualitas Pelayanan terhadap loyalitas nasabah melalui kepuasan nasabah sebagai variabel mediasi adalah 0,229. Artinya hipotesis keenam yang menyatakan terdapat pengaruh antara kualitas pelayanan terhadap loyalitas nasabah PT BRI Cabang Purwokerto 
melalui kepuasan nasabah sebagai variabel mediasi, diterima dengan pengaruh sebesar 0,229.

Menurut Alfred (2013:183) kualitas mempengaruhi harapan pelanggan dan sejauh mana pelanggan atau pengguna percaya produk atau jasa melampaui mereka kebutuhan dan harapan. Menurut Shaharudin et al, (2010) kualitas produk adalah faktor yang paling penting bagi pemilihan masing-masing merek terutama di lingkungan pasar di mana tingkat persaingan sangat ketat. Menurut Asgar Afshar (2011), menunjukkan bahwa kualitas produk mendukung dan signifikan terhadap kepuasan konsumen.

Penelitian Shandra (2016) berjudul Kepuasan Konsumen Sebagai Mediasi Pengaruh Kualitas Pelayanan, Brand Image, Dan Harga Terhadap Loyalitas Konsumen. Hasil penelitian menunjukkan bahwa kualitas pelayanan berpengaruh signifikan terhadap loyalitas konsumen melalui kepuasan konsumen, brand image berpengaruh signifikan terhadap loyalitas konsumen melalui kepuasan konsumen dan harga berpengaruh signifikan terhadap loyalitas konsumen melalui kepuasan konsumen. Simpulan dari penelitian ini terbukti bahwa kepuasan konsumen memiliki peran sebagai variabel intervening antara kualitas pelayanan, brand image, dan harga terhadap loyalitas konsumen.

Loyalitas konsumen menjadi masalah setiap perusahaan, karena konsumen memiliki kebebasan dalam memilih dan terdapat banyak pilihan yang menawarkan berbagai produk unggulan untuk menarik konsumen.Hal ini didasarkan atas expectancy disconfirmation theory yang menyatakan bahwa niat pelanggan untuk membeli kembali produk atau menggunakan kembali layanan ditentukan terutama oleh kepuasan mereka dengan penggunaan sebelumnya dari produk atau layanan (Liao, et al, 2011).

\section{KESIMPULAN}

\section{Kesimpulan}

Hasil penelitian menunjukkan terdapat pengaruh positif signifikan variabel kualitas pelayanan terhadap kepuasan nasabah.Citraberpengaruh positif signifikan terhadap kepuasan nasabah. Tidak terdapat pengaruh variabel citra terhadap loyalitas pelanggan. Terdapat pengaruh positif signifikan variabel kualitas pelayanan terhadap loyalitas pelanggan. Terdapat pengaruh positif signifikan variabel kepuasan nasabah terhadap loyalitas pelanggan. Terdapat pengaruh kualitas pelayanan terhadap loyalitas nasabah melalui kepuasan nasabah sebagai variabel mediasi Bank BRI Cabang Purwokerto. Dan terdapat pengaruh citra terhadap loyalitas nasabah melalui kepuasan nasabah sebagai variabel mediasi Bank BRI Cabang Purwokerto.

\section{Implikasi Kebijakan}

Loyalitas nasabah di Bank BRI Cabang Purwokerto sangat dipengaruhi oleh variabel kualitas pelayanan, citra dan kepuasan nasabah sebagai variabel mediasi. Kualitas pelayanan dan kepuasan nasabah mempunyai keterikatan satu sama lain. Hal tersebut dapat meningkatkan loyalitas nasabah. Agar nasabah loyal, maka Bank BRI Cabang Purwokerto harus mengerti keinginan nasabah agar nasabah merasa bahwa dirinya dihargai.

Terkait dengan citra perusahaan, Bank BRI Cabang Purwokerto perlu mempertahankan dan meningkatkan kualitas kerja karyawan. Manajemen Bank BRI Cabang Purwokerto perlu meningkatkan kemampuan para karyawan dalam menanamkan kepercayaan kepada nasabah, adanya perasaan aman bagi nasabah dalam melakukan transaksi, serta pengetahuan dan sopan santun karyawan dalam memberikan layanan kepada nasabah, pengetahuan, kesopanan dan kemampuan karyawan akan menimbulkan kepercayaan dan keyakinan terhadap perusahaan karena mampu meningkatkan loyalitas nasabah.

Terkait dengan kepuasan nasabah, Bank BRI Cabang Purwokerto perlu memberikan pelatihan-pelatihan dalam meningkatkan kompetensi kerjanya agar lebih menguasai job desknya memberikan pelatihan-pelatihan yang terrkait dengan emotional question dan 
meningkatkan teamwork Manajemen Bank BRI Cabang Purwokerto perlu meningkatkan kecepatan, ketepatan layanan yang diberikan kepada nasabah, keinginan karyawan untuk membantu para nasabah, serta adanya karyawan pada jam-jam sibuk karena mampu meningkatkan loyalitas nasabah.

Bank BRI Cabang Purwokerto perlu meningkatkan perhatian atau kepedulian karyawan kepada pelanggan, kemudahan mendapatkan layanan (berkaitan kemudahan mendapatkan informasi melalui telepon). Kepedulian karyawan terhadap masalah yang dihadapinya mampu meningkatkan loyalitas nasabah.

Karena kualitas pelayanan berpengaruh secara signifikan terhadap loyalitas nasabah maka hendaknya menambahkan fasilitas seperti kotak saran di bagian depan sebagai tempat menampung kritik dan saran yang di berikan langsung oleh konsumen untuk bisa meningkatkan kualitas pelayanan sesuai keinginan para nasabah.

Untuk lebih meningkatkan loyalitas nasabah perlu ditingkatkan kualitas pelayanan kepada nasabah seperti, mengurangi waktu tunggu nasabah dalam bertransaksi, memberikan fasilitas jemput bola kepada nasabah yang ingin menempatkan dananya.

\section{Implikasi Teoritis}

Berdasarkan penelitian-penelitian yang telah dilakukan sebelumnyaditemukan adanya beberapa perbedaan yang mendasar mengenai adanya fenomena research gap (hasil penelitian yang berbeda) antara penelitiandilakukan oleh Gracia (2012) menunjukkan bahwa variabel citra berpengaruh positif signifikan terhadap loyalitas. Sedangkan penelitianChasbulloh (2013) menunjukkan bahwa citra perusahaan berpengaruh positif tidak signifikan terhadap loyalitas pelanggan. Research gap ini mendapat jawaban daripenelitian ini bahwa citratidak berpengaruhlangsung terhadap loyalitas pelanggan dan penelitian ini menunjukkan bahwa citra akan berpengaruh terhadap loyalitas pelangganapabila melalui kepuasan nasabah sebagai variabel mediasi.

Terkait dengan beberapa keterbatasan dalam penelitian ini, maka penelitian selanjutnya perlu menambahkan variabel-variabel bebas lainnya misalnya kualitas produk. Dan jika dimungkinkan penelitian selanjutnya juga perlu melakukan pengembangan model penelitian terkait dengan dampak loyalitas nasabah terhadap keunggulan bersaing.Juga perlu menambahkan jumlah sampel serta memperluas cakupan penelitian agar hasilnya dapat lebih agar lebih komprehensif dan dapat digeneralisirkan.

\section{DAFTAR PUSTAKA}

Afshar, Asghar. 2011. Study the Effects of Customer Service and Product Quality on Customer Satisfaction and Loyalty. International Journal of Humanities and Social Science, Vol. 1(7).

Alfred, Owusu, 2013. Influences of Price And Quality On Consumer PurchaseOf MobilePhone In The Kumasi Metropolis In Ghana A Comparative Study,Ghana, European Journal of Bussiness and Management, Vol. 5, No. 1, 2013

Ali, R., Leifu, P.G., dan Rehman, R.U. 2014.Factors Influencing Customer Loyalty of Banking Industry : Emperical Evidence from Pakistan. International Journal of Learning and Development. Vol. 4, No. 2, 1-47.

Armstrong, Kotler 2015, "Marketing an Introducing Prentice Hall twelfth edition", England: Pearson Education, Inc

Bedi, M. (2010). An Integrated Framework for Service Quality, Customer Satisfaction and Behavioral Responses in Indian Banking Industry-aComparison of Public and Private, Journal of Services Research, Vol. 10 No. 1, pp. 157- 172. 
Bilika, F., Safari, M., Mansori, S., 2016. Service Quality and Customer Satisfaction in Mozambique Banking System. Journal of Marketing Management and Consumer Behavior. Vol. 1.

Chasbulloh, M. Romy. 2013. Pengaruh Kualitas Layanan, Kepercayaan Pelanggan, Citra Perusahaan Dengan Kepuasan Terhadap Loyalitas Pada Giant Hypermarket Di Surabaya. STIE Perbanas Surabaya.

Dimyati. 2016. Impact of Service Quality, Price, and Brand on Loyalty with the mediation of Customer Satisfaction on Pos Ekspres in East Java. Mediterranean Journal of Social Sciences. Vol 7 No 4

Faizan Mohsan, et al. (2011) Impact Of Customer Satisfaction On Customer Loyalty And Intentions To Switch: Evidence From Banking Sector Of Pakistan. International Journal of Business and Social Science Vol. 2 No. 16; September 2011

Gracia, P.D. (2012). Pengaruh Citra perusahaan dan Nilai terhadap Loyalitas Nasabah dengan dimoderasi Lama menjadi Nasabah.Jurnal Manajemen dan Akutansi.Vol. 3, No.5, 1-26.

Hafeez, Samraz \& Muhammad, Bakhtiar. 2012. The Impact of Service Quality, Customer Satisfaction and Loyalty Programs on Customer's Loyalty: Evidence from Banking Sector of Pakistan, 3(16), 200-209.

Hawkins, D.I, dan Mothersbaugh, D.L. 2010. Consumer Behavior: Building Marketing Strategy.11th edition. McGraw -Hill, Irwin.

Hu, K.C., and Huang, M.C. (2011). Effect of service quality, innovation and corporate image on customer satisfaction and loyalty of Air cargo terminal. International Journal of Operations Research Vol.8, No. 4, 36-47.

Infobank, Mei 2018.

Ishaq Muhammad Ishtiaq et al., 2014. Role of Corporate Image, Product Quality and Customer Value in Customer Loyalty: Intervening Effect of Customer Satisfaction.

Jahanshahi, A., Gashti, M. A. H., Mirdamadi, S. A., Nawaser, K.,\& Khaksar, S. M. S. (2011). Study the effects of customerservice and poduct quality on customer satisfaction andloyalty. International Journal of Humanities and SocialScience 1(7), 253-260

Kurniawati, Dewi. 2014. Pengaruh Citra Merek dan Kualitas Produk Terhadap Kepuasan dan Loyalitas Pelanggan. Jurnal Administrasi Bisnis (JAB),Vol. 14(2).

Liao, Chechen, Chuang-Chun Liu, Yu-Ping Liu, Pui-Lai To, and Hong-Nan Lin. 2011. Applying the Expectancy Disconfirmation and Regret Theories to Online customer Behavior. Cyberpsychology, Behavior, And Social Networking. Volume 14, Number 4.

Martina et al. (2013) The Quality value, satisfaction, loyalty chain : relationships and impacts. VOL. 68 NO. 1 2013, pp. 3-20, Emerald Group Publishing Limited, ISSN 1660-5373

Qomariyah, Nurul (2012) Pengaruh Kualitas Layanan dan Citra Institusi terhadap Kepuasan dan Loyalitas Pelanggan. Jurnal Aplikasi Manajemen Vol 1 o No.1

Rizwan Ali, et al. 2014. Factors Influencing Customer Loyalty of Banking Industry : Empirical Eviden from Pakistan. International Journal of Learning \& Development ISSN 216440632014, Vol. 4, No. 2 
Robbins, Stephen P \& Judge, Timothy A. 2013. Organizational Behavior Edition 15. New Jersey: Pearson Education.

Santouridis, Ilias dan Panagiotis Trivellas. 2010. Investigating The Impact Of Service Quality And Customer Satisfaction on Customer Loyalty In Mobile Telephony In Greece. The TQM Journal, 22, $330-343$

Shaharudin, R.M., Anita, A.H., Mansor, S.W., Elias, H.H., and Nurazila, A.A. 2010. The Relationship between Extrinsic Attributes of Product Quality with Brand Loyalty on Malaysia National Brand Motorcycle/Scooter. CanadianSocial Science, 6 (3), pp: 165-175.

Shandra, M.P.K. 2016.Kepuasan Konsumen Sebagai Mediasi Pengaruh Kualitas Pelayanan, Brand Image, Dan Harga Terhadap Loyalitas Konsumen.Vol 5 No 1 (2016): Management Analysis Journal

Sumertana, I Wayan. 2016. Pengaruh Kualitas Pelayanan terhadap Loyalitas Pelanggan dengan Kepuasan Pelanggan sebagai Variabel Intervening pada Water Park Seririt Singaraja tahun 2014-2015. Jurnal Program Studi Pendidikan Ekonomi. 7(2), 1-10.

Sutisna, 2011. "Konsep Citra".(http://notasimediori.wordpress.com).

Syaifuddin, 2016. Pengaruh Kualitas Layanan Terhadap Loyalitas Melalui Kepuasan Pelanggan Sebagai Variabel Intervening (Studi kasus : Kereta Jenggala jurusan MojokertoSidoarjo).Program studi manajemen, Universitas Narotama.

Tjiptono, F. dkk. 2012. Pemasaran Jasa.Yogyakarta: CV Andi Offset.

Tutut, Ratna. 2011. Pengaruh Brand Image terhadap Loyalitas Pengguna Smartphone Iphone. Jurnal Fakultas Komunikasi dan Bisnis Universitas Telkom 